\title{
Antibacterial Activity of Stenotrophomonas maltophilia Endolysin P28 against both Gram-Positive and Gram-Negative Bacteria
}

\author{
Hongling Dong ${ }^{1}$, Chaoyang Zhu ${ }^{1}$, Jingyi Chen ${ }^{1}$, Xing Ye ${ }^{1}$ and Yu-Ping Huang ${ }^{1,2 *}$ \\ ${ }^{1}$ College of Life Sciences, Wuhan University, Wuhan, China, ${ }^{2}$ Hubei Provincial Cooperative Innovation Center of Industrial \\ Fermentation, Wuhan, China
}

OPEN ACCESS

Edited by:

Joanna S. Brooke,

DePaul University, USA

Reviewed by:

Deborah R. Yoder-Himes,

University of Louisville, USA

Paras Jain

Albert Einstein College of Medicine,

USA

${ }^{*}$ Correspondence: Yu-Ping Huang

yphuang@whu.edu.cn

Specialty section: This article was submitted to

Infectious Diseases,

a section of the journal

Frontiers in Microbiology

Received: 19 June 2015 Accepted: 06 November 2015 Published: 24 November 2015

Citation:

Dong H, Zhu C, Chen J, YeX and Huang Y-P (2015) Antibacterial

Activity of Stenotrophomonas maltophilia Endolysin P28 against both Gram-Positive

and Gram-Negative Bacteria.

Front. Microbiol. 6:1299.

doi: 10.3389/fmicb.2015.01299
Maltocin P28 is a phage-tail like bacteriocin produced by Stenotrophomonas maltophilia P28. The ORF8 of maltocin P28 gene cluster is predicted to encode an endolysin and we name it endolysin P28. Sequence analysis revealed that it contains the lysozyme_like superfamily conserved domain. Endolysin P28 has the four consensus motifs as that of Escherichia coli phage lambda gpR. In this study, endolysin P28 was expressed in E. coli BL21 (DE3) and purified with a C-terminal oligo-histidine tag. The antibacterial activity of endolysin P28 increased as the temperature rose from 25 to $45^{\circ} \mathrm{C}$. Thermostability assays showed that endolysin $\mathrm{P} 28$ was stable up to $50^{\circ} \mathrm{C}$, while its residual activity was reduced by $55 \%$ after treatment at $70^{\circ} \mathrm{C}$ for $30 \mathrm{~min}$. Acidity and high salinity could enhance its antibacterial activity. Endolysin P28 exhibited a broad antibacterial activity against 14 out of 16 tested Gram-positive and Gram-negative bacteria besides S. maltophilia. Moreover, it could effectively lyse intact Gram-negative bacteria in the absence of ethylenediaminetetraacetic acid as an outer membrane permeabilizer. Therefore, the characteristics of endolysin P28 make it a potential therapeutic agent against multi-drug-resistant pathogens.

\section{Keywords: endolysin, Stenotrophomonas maltophilia, antibacterial activity, maltocin, EDTA}

\section{INTRODUCTION}

Stenotrophomonas maltophilia is a Gram-negative bacillus and increasingly being recognized as an important nosocomial pathogen (Looney et al., 2009; Brooke, 2012). It can cause serious infections such as bacteremia, pneumonia, endocarditis, meningitis, urinary tract infections, skin and soft tissue infections in immunocompromised patients (Falagas et al., 2009; Sood et al., 2013; Hotta et al., 2014; Trignano et al., 2014; Guzoglu et al., 2015). The available therapeutic option for invasive S. maltophilia infection is limited, as this pathogen shows high levels of resistance to commonly used antibiotics (Sánchez, 2015). S. maltophilia not only exhibits intrinsic multidrug resistance but also can acquire antibiotic resistance during therapy like other pathogenic strains (Tan et al., 2008). Therefore, the novel treatment strategies and the effective antimicrobial agents are needed urgently to date for treatment of S. maltophilia infections. 
Endolysins are enzymes encoded by phages at the end of their replication cycle to degrade the peptidoglycan of the host cell wall for cell lysis and release of the mature progeny phage particles (Loessner, 2005). Due to the absence of an outer membrane in Gram-positive bacteria, endolysins can easily access the peptidoglycan of cell wall and destroy these organisms when applied externally (Fischetti, 2010; Gilmer et al., 2013). When the endolysins work with Gram-negative bacteria, the chelating agents, like ethylenediaminetetraacetic acid (EDTA), are often used to increase the bacterial outer membrane permeability (Briers et al., 2011; Walmagh et al., 2013). Endolysins have been reported to be applied in medicine, control and detection of food-borne pathogens (Fischetti, 2008; Grandgirard et al., 2008; Coffey et al., 2010; Schmelcher et al., 2012). Endolysins can also be expressed by transgenic plants to prevent infection by phytopathogenic bacteria (Oey et al., 2009). Expanding databases of predicted proteins from the increasing number of sequenced and annotated bacterial genomes present a growing number of potential endolysins (Schmitz et al., 2010; Farris and Steinberg, 2014). As multidrug-resistant strains are becoming more prevalent, endolysins may be employed as novel alternatives to antibiotics (Bragg et al., 2014; Yang et al., 2014).

In the previous work, we have identified the maltocin P28 from S. maltophilia P28. The gene cluster of maltocin P28 is presumed to have 23 open reading frames (ORFs), and ORF8 is predicted to encode an endolysin (Liu et al., 2013). Here we designate this putative endolysin as endolysin P28. Sequence analysis revealed that the endolysin P28 contained the lysozymelike superfamily conserved domain and its amino acid sequence had high identity with that of lambda phage gpR. In this study, we cloned the ORF8 into pET-26b(+) to express this endolysin gene in Escherichia coli. The recombinant endolysin P28 was purified and characterized. And the antibacterial activity of endolysin P28 against various Gram-negative and Gram-positive bacteria was also detected.

\section{MATERIALS AND METHODS}

\section{Bacterial Strains and Growth Conditions}

Stenotrophomonas maltophilia P28 and E. coli BL21(DE3) were routinely cultivated in $\mathrm{LB}$ broth at $30^{\circ} \mathrm{C}$. One hundred microgram per milliliter of ampicillin or $50 \mu \mathrm{g} / \mathrm{mL}$ kanamycin was added when necessary. Strains used for antimicrobial spectrum determination were all cultured in LB broth. The growth temperature was listed in Table 1. Most tested strains were taken from China Center for Type Culture Collection (CCTCC), the others were purchased from the American Type Culture Collection (ATCC) and Aeromonas hydrophila strain XS91-4-1 was kindly provided by Professor Aihua Li at Institute of Hydrobiology, Chinese Academy of Sciences.

\section{Plasmid Construction and Transformation}

DNA manipulations were performed according to standard protocols (Sambrook, 1989). Genomic DNA of S. maltophilia P28
TABLE 1 | Antimicrobial activity of endolysin P28 against various species.

\begin{tabular}{|c|c|c|c|}
\hline Strain & Species & $\begin{array}{c}\text { Growth } \\
\text { temperature } \\
\left({ }^{\circ} \mathrm{C}\right)\end{array}$ & $\begin{array}{c}\text { Antibacterial } \\
\text { rate }(\%)\end{array}$ \\
\hline
\end{tabular}

Gram-positive bacteria

CCTCC $^{a}$

AB200055

Bacillus subtilis

CCTCC AB93017

30

$>99$

Listeria monocytogenes

CCTCC AB209106

CСTCC AB91053

\section{0}

$>99$

Staphylococcus aureus

Gram-negative bacteria

Aeromonas hydrophila

XS91-4-1

Aeromonas salmonicida

Enterobacter aerogenes

Escherichia coli

CCTCC AB98041

CCTCC AB91102

ATCC47076

Klebsiella pneumoniae

ssp. pneumoniae

CCTCC

AB2010163

Proteus vulgaris

CCTCC AB91103

ATCC 15692

Pseudomonas

aeruginosa

Pseudomonas

fluorescens

Pseudomonas putida

Salmonella typhimurium

Shigella flexneri

Xanthomonas citri ssp.

CCTCC AB92001

ATCC12633

CСTCC AB204062

СCTCC AB200061

CCTCC AB96030

\section{0}

90.4

90.4
$>99$

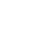

$30 \quad 47.1$

$22 \quad 19.2$

$37 \quad 58.3$

$37 \quad 60.3$

$37 \quad>99$

$30 \quad 61.2$

$30 \quad 70.6$

$30 \quad 0$

$30 \quad 34.7$

$37 \quad 0$

$37>99$

$30>99$

malvacearum

${ }^{a}$ CCTCC, China Centre for Type Culture Collection.

was extracted using the genomic DNA extraction kit (TIANGEN, China) and used as the template to amplify the ORF8 of maltocin P28 gene cluster. Plasmid DNA was obtained with TIANprep Mini Plasmid kit (TIANGEN, China).

\section{Cloning, Expression, and Purification of Endolysin P28}

The ORF8 (putative endolysin gene) was amplified from the genomic DNA of $S$. maltophilia P28 by polymerase chain reaction (PCR). The PCR primers were endo-F (5' -CATATGACCGCCGC TGCAGCCAG-3') and endo-R (5'-CTCGAGCTGCAGGGCTC CGCC-3'). Amplification was performed in PTC100 (BioRad, USA) with the following condition: $95^{\circ} \mathrm{C}$ for $5 \mathrm{~min}, 30$ cycles of $94^{\circ} \mathrm{C}$ for $30 \mathrm{~s}, 55^{\circ} \mathrm{C}$ for $30 \mathrm{~s}, 72^{\circ} \mathrm{C}$ for $30 \mathrm{~s}$, and the final extension with $72^{\circ} \mathrm{C}$ for $10 \mathrm{~min}$. The PCR product was purified with Cycle-pure-Kit (OMEGA) and cloned into pDM19-T vector to confirm the sequence. Then the recombinant plasmid pDM19-T-ORF8 was digested with restriction enzymes NdeI and XhoI. The obtained 492-bp fragment was purified and inserted into pET-26b $(+)$ by NdeI and XhoI, designating the recombinant plasmid pET26b-ORF8. The E. coli BL21 (DE3) was transformed with plasmid pET-26b-ORF8. Transformants were cultivated in $\mathrm{LB}$ broth containing $50 \mu \mathrm{g} / \mathrm{mL}$ kanamycin at $37^{\circ} \mathrm{C}$. Protein expression was induced by adding $1 \mathrm{mM}$ isopropyl- $\beta-\mathrm{D}-$ thiogalactopyranoside (IPTG) at $\mathrm{OD}_{600}$ 0.5-0.8, followed by incubation for $6 \mathrm{~h}$ at $30^{\circ} \mathrm{C}$. Bacterial cells were harvested at 
$4^{\circ} \mathrm{C}$, suspended in binding buffer $(0.5 \mathrm{M}$ sodium chloride, $50 \mathrm{mM}$ Tris-HCl, $\mathrm{pH}$ 7.5), and disrupted by sonication on ice. The lysates were centrifugated at $13,000 \mathrm{~g}$ for $10 \mathrm{~min}$. After centrifugation, the supernatant was passed through a Ni-NTA column (Novagen). Purification of endolysin P28 was performed according to the manufacturer's instructions. The identity and purity of the protein were confirmed by sodium dodecyl sulfate-polyacrylamide gel electrophoresis (SDS-PAGE). The gel was stained by Coomassie brilliant blue R-250 to visualize the bands. The purified endolysin P28 was stored at $-20^{\circ} \mathrm{C}$ after the buffer was changed to the storage buffer $(20 \mathrm{mM}$ Tris- $\mathrm{HCl}, \mathrm{pH} 7.0)$ by ultrafiltration.

\section{Determination of the Lytic Activity}

The antibacterial activity of endolysin P28 was assessed by CFU reduction analysis as described previously (Rodriguez et al., 2011). Exponentially growing cells were centrifuged to discard the supernatant, and then the cell pellet was washed twice, resuspended in $20 \mathrm{mM}$ Tris- $\mathrm{HCl}$ buffer $(\mathrm{pH}$ 7.0) and adjusted the $\mathrm{OD}_{600}$ to $0.5 \pm 0.05$. Purified endolysin $(100 \mu \mathrm{L})$ was added to $300 \mu \mathrm{L}$ cell suspension. The volume of reaction system was $400 \mu \mathrm{L}$. Generally the concentration of the endolysin added was adjusted to $2 \mathrm{mg} / \mathrm{mL}$ and the working concentration was $0.5 \mathrm{mg} / \mathrm{mL}$. When the appropriate working concentration was tested, the concentration of the purified endolysin was changed while the reaction volumes of purified endolysin $(100 \mu \mathrm{L})$ and cell suspension $(300 \mu \mathrm{L})$ remained unchanged. After incubation for $1 \mathrm{~h}$ at $30^{\circ} \mathrm{C}$, the mixture was serially diluted by 10 -fold. To determine the survival rate, $100 \mu \mathrm{L} 10$ fold serial dilutions were plated on LB agar in triplicate, then colony forming units (CFUs) were counted after incubation at $30^{\circ} \mathrm{C}$ for $24 \mathrm{~h}$. The number of CFUs between 30 and 300 on the spread plate was effectively counted. The control was performed by adding $100 \mu \mathrm{L} 20 \mathrm{mM}$ Tris- $\mathrm{HCl}$ buffer $(\mathrm{pH}$ 7.0) instead of endolysin P28. The antibacterial activity was expressed as the bacterial counts decrease. This value was calculated as the dead percentage referred to an untreated control. In this study, all the data were statistically analyzed by using the Origin 8.1 program. Difference was investigated by the $T$-test at the $5 \%$ level. All experiments were repeated at least three times. The error bars represent the standard deviations.

In order to analyze the effect of EDTA, the above washed S. maltophilia culture $\left(\mathrm{OD}_{600} 0.5 \pm 0.05\right)$ was incubated in $20 \mathrm{mM}$ Tris-HCl buffer ( $\mathrm{pH} 7.0$ ) containing $0,1 \mathrm{mM}$ and $5 \mathrm{mM}$ EDTA for $30 \mathrm{~min}$. After centrifugation to remove the EDTA, the cell pellet was resuspended in $20 \mathrm{mM}$ Tris- $\mathrm{HCl}$ buffer $(\mathrm{pH}$ 7.0). Then the purified endolysin was added and its antibacterial activity was determined as described above.

To evaluate the effect of $\mathrm{pH}$ on endolysin lytic activity, the endolysin $(100 \mu \mathrm{L}, 2.0 \mathrm{mg} / \mathrm{mL})$ was added to $300 \mu \mathrm{L}$ S. maltophilia cells suspended with a variety of buffers: $20 \mathrm{mM}$ $\mathrm{NaAc}$ for $\mathrm{pH} 4.0$ and $\mathrm{pH} 5.0,20 \mathrm{mM} \mathrm{Na}_{2} \mathrm{HPO}_{4}-\mathrm{NaH}_{2} \mathrm{PO}_{4}$ for $\mathrm{pH}$ 6.0, $20 \mathrm{mM}$ Tris- $\mathrm{HCl}$ for $\mathrm{pH} 7.0, \mathrm{pH} 8.0$ and $\mathrm{pH}$ 9.0, Glycine- $\mathrm{NaOH}$ for $\mathrm{pH} 10.0-12.0$. The control was carried out by adding $100 \mu \mathrm{L}$ respective buffer instead of endolysin P28.
After incubation for $1 \mathrm{~h}$ at $30^{\circ} \mathrm{C}$, the CFUs of the mixture were determined by 10 -fold dilution and the antibacterial activity was calculated as described above.

The influence of saline concentration on the lytic activity of endolysin was tested with $\mathrm{NaCl}$ concentration from 50 to $400 \mathrm{mM}$ to cell suspension. One hundred microliter purified endolysin $(2.5 \mathrm{mg} / \mathrm{mL})$ was added to $300 \mu \mathrm{L}$ exponentially growing cell $\left(\mathrm{OD}_{600} 0.5 \pm 0.05\right)$, which was washed and resuspended in $20 \mathrm{mM}$ Tris- $\mathrm{HCl}$ buffer ( $\mathrm{pH}$ 7.0). And then $100 \mu \mathrm{L} \mathrm{NaCl}$ solution of different concentration was added to the mixture. The control was performed by adding $100 \mu \mathrm{L} 20 \mathrm{mM}$ Tris- $\mathrm{HCl}$ buffer $(\mathrm{pH}$ 7.0) instead of endolysin P28. After incubation for $1 \mathrm{~h}$ at $30^{\circ} \mathrm{C}$, the CFUs were determined by 10 -fold dilution and the antibacterial activity was calculated as described above.

In order to examine the effect of different temperatures on the enzymatic activity of endolysin P28, $100 \mu \mathrm{L}$ purified endolysin $(2.0 \mathrm{mg} / \mathrm{mL})$ was added to $300 \mu \mathrm{L}$ exponentially growing cell $\left(\mathrm{OD}_{600} 0.5 \pm 0.05\right)$, which was washed and resuspended in $20 \mathrm{mM}$ Tris- $\mathrm{HCl}$ buffer ( $\mathrm{pH}$ 7.0). The control was performed by adding $100 \mu \mathrm{L} 20 \mathrm{mM}$ Tris- $\mathrm{HCl}$ buffer ( $\mathrm{pH}$ 7.0) instead of endolysin P28. After incubation for $1 \mathrm{~h}$ at different temperatures $\left(25-45^{\circ} \mathrm{C}\right)$, the CFUs were determined by 10 -fold dilution and the antibacterial activity was calculated as described above.

Thermostability was tested by incubating endolysin P28 $(2.0 \mathrm{mg} / \mathrm{mL})$ in $30,40,50,60,70$ for $30 \mathrm{~min}$, and then $100 \mu \mathrm{L}$ treated endolysin P28 was mixed with the above washed $S$. maltophilia cells $\left(\mathrm{OD}_{600} 0.5 \pm 0.05\right)$. The control was performed by adding $100 \mu \mathrm{L} 20 \mathrm{mM}$ Tris- $\mathrm{HCl}$ buffer $(\mathrm{pH} 7.0)$ instead of endolysin P28. After incubation for $1 \mathrm{~h}$ at $30^{\circ} \mathrm{C}$, the CFUs of the mixture were determined by 10 -fold dilution and the antibacterial activity was calculated as described above.

\section{RESULTS}

\section{Sequence Analysis}

Maltocin P28 is a novel phage tail-like bacteriocin produced by S. maltophilia P28 and has been characterized previously (Liu et al., 2013). The ORF8 of maltocin P28 gene cluster was predicted to encode an endolysin designated as endolysin P28. The deduced amino acid of endolysin P28 showed $48.48 \%$ identity with that of phage lambda gpR, which is the lambda lysozyme and function as a lytic transglycosylase. NCBI Blastp revealed that endolysin P28 included a conserved domain known as bacteriophage_lambda_lysozyme family. This family of lysozymes contains four consensus motifs (Blackburn and Clarke, 2001). Endolysin P28 has the same motifs, with the essential catalytic residue (Glu25) in motif I as lambda lysozyme gpR (Jespers et al., 1992) (Figure 1A). Compared with lambda gpR, endolysin $\mathrm{P} 28$ contained an N-terminal hydrophobic region (Figure 1B).

\section{Expression and Purification of Endolysin P28}

Endolysin P28 was overproduced as a C-terminal $6 \times$ Histagged fusion protein which allowed purification by immobilized metal chelate affinity chromatography. The elution fractions 


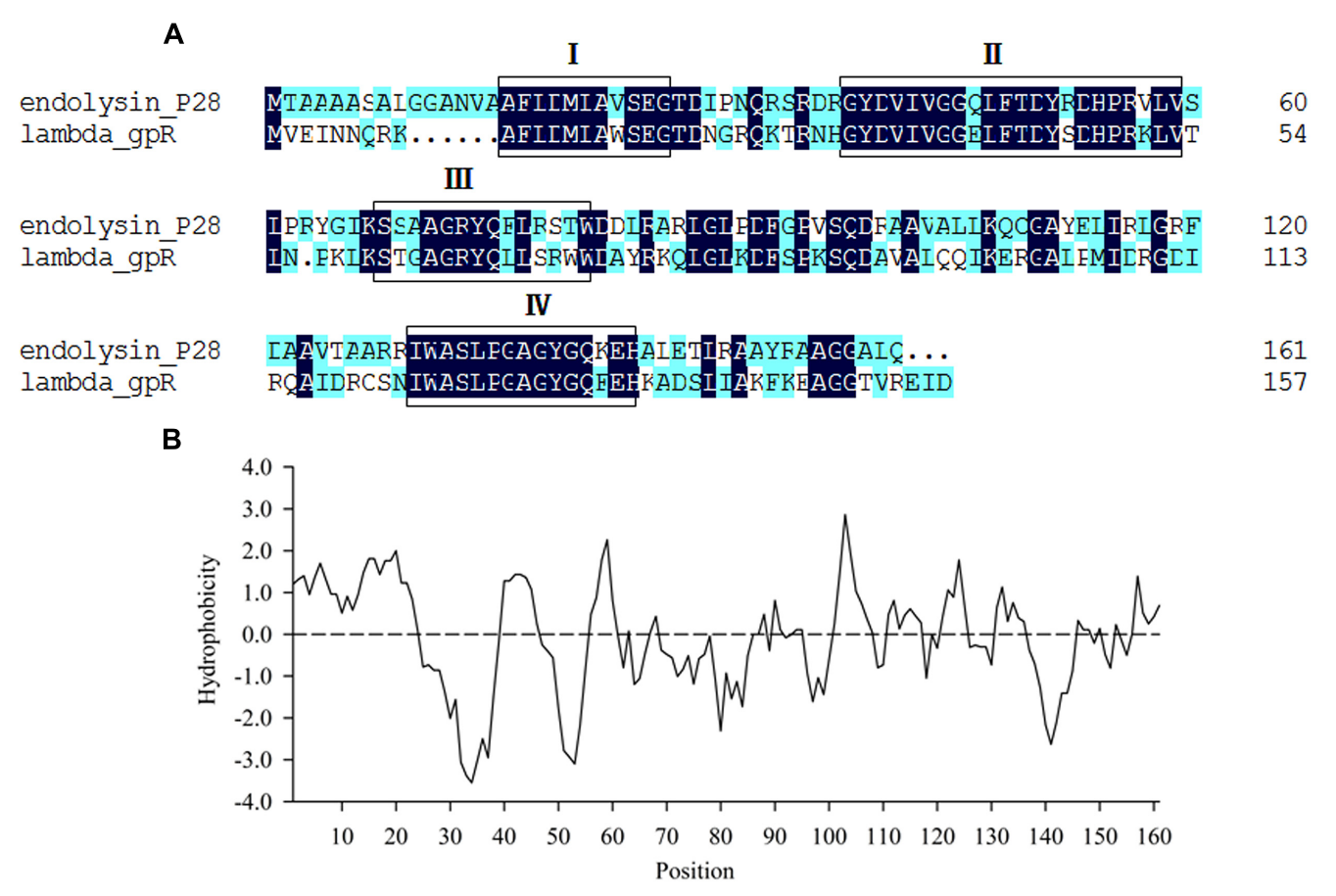

FIGURE 1 | Sequence analysis of endolysin P28. (A) Comparison of amino acid sequences between endolysin P28 and lambda gpR, the boxes indicate the four consensus motifs. (B) Hydrophobicity analysis of endolysin P28.

were pooled and analyzed by $15 \%$ SDS-PAGE. A major protein band was observed which correlated well with the calculated mass of the endolysin P28 fusion protein (18.1 kDa; Figure 2). The concentration of purified endolysin P28 was determined according to the Bradford assay.

\section{Lytic Activity of Endolysin P28}

For antibacterial activity measurement, S. maltophilia P28 was used as substrate for the purified endolysin. The lytic activity of endolysin P28 was conducted by CFU reduction assay. The addition of $125 \mu \mathrm{g} / \mathrm{mL}$ endolysin did not change the viable numbers of $S$. maltophilia. When the endolysin concentration rose more than $125 \mu \mathrm{g} / \mathrm{mL}$, its antibacterial activity enhanced as the concentration increased (Figure 3). When the endolysin concentration was $500 \mu \mathrm{g} / \mathrm{mL}$, the CFU number reduced about a half. Thus the endolysin concentration of $500 \mu \mathrm{g} / \mathrm{mL}$ was used as the standard to perform the following antibacterial assays.

Gram-negative bacteria are more sensitive to endolysins after they are treated with EDTA to enhance the permeability of their outer membrane (Briers et al., 2011). To determine the effect of EDTA on the antimicrobial activity of endolysin P28, both S. maltophilia P28 and Pseudomonas aeruginosa ATCC15692 were treated with the different concentrations of EDTA for $30 \mathrm{~min}$. The addition of EDTA led the cell lysis of $P$. aeruginosa ATCC15692 to significantly increase compared with buffer alone. The viable cell number of $P$. aeruginosa ATCC15692 was reduced more than 2 logs by addition of $1 \mathrm{mM}$ EDTA, while the sensitivity of $S$. maltophilia
P28 to endolysin was not affected by addition of EDTA (Figure 4). Thus, we did not add EDTA in the following experiments.

\section{Influence of Temperature, Salinity, and pH on Endolysin P28 Antibacterial Activity}

Standard CFU reduction analysis was performed to analyze the effects of temperature, salinity, and $\mathrm{pH}$ on endolysin P28 antibacterial activity. The results showed that the antibacterial activity increased with the increase of temperature from 25 to $45^{\circ} \mathrm{C}$ (Figure 5A ). And as the salt concentration increased from $100 \mathrm{mM}$ to $200 \mathrm{mM}$, the antibacterial activity increased sharply. While the salt concentration up to $400 \mathrm{mM}$ did not enhance the antibacterial activity further (Figure 5C). As for the effect of $\mathrm{pH}$ on endolysin $\mathrm{P} 28$, the result revealed that it had a relatively high lytic activity at a broad $\mathrm{pH}$ range of 5.0-8.0 and was ineffective when $\mathrm{pH}$ rose to 11.0 (Figure 5B). The thermal stability of endolysin P28 was characterized by challenges over a range of temperatures (30, $40,50,60$, and $70^{\circ} \mathrm{C}$ ). Residual activity of endolysin P28 was reduced $55 \%$ by following treatment at $70^{\circ} \mathrm{C}$ for $30 \mathrm{~min}$ (Figure 5D).

\section{Antibacterial Spectrum}

To test the antibacterial spectrum of endolysin P28, we used four Gram-positive and twelve Gram-negative bacteria as substrates. Maltocin P28 only lyses S. maltophilia (Liu et al., 

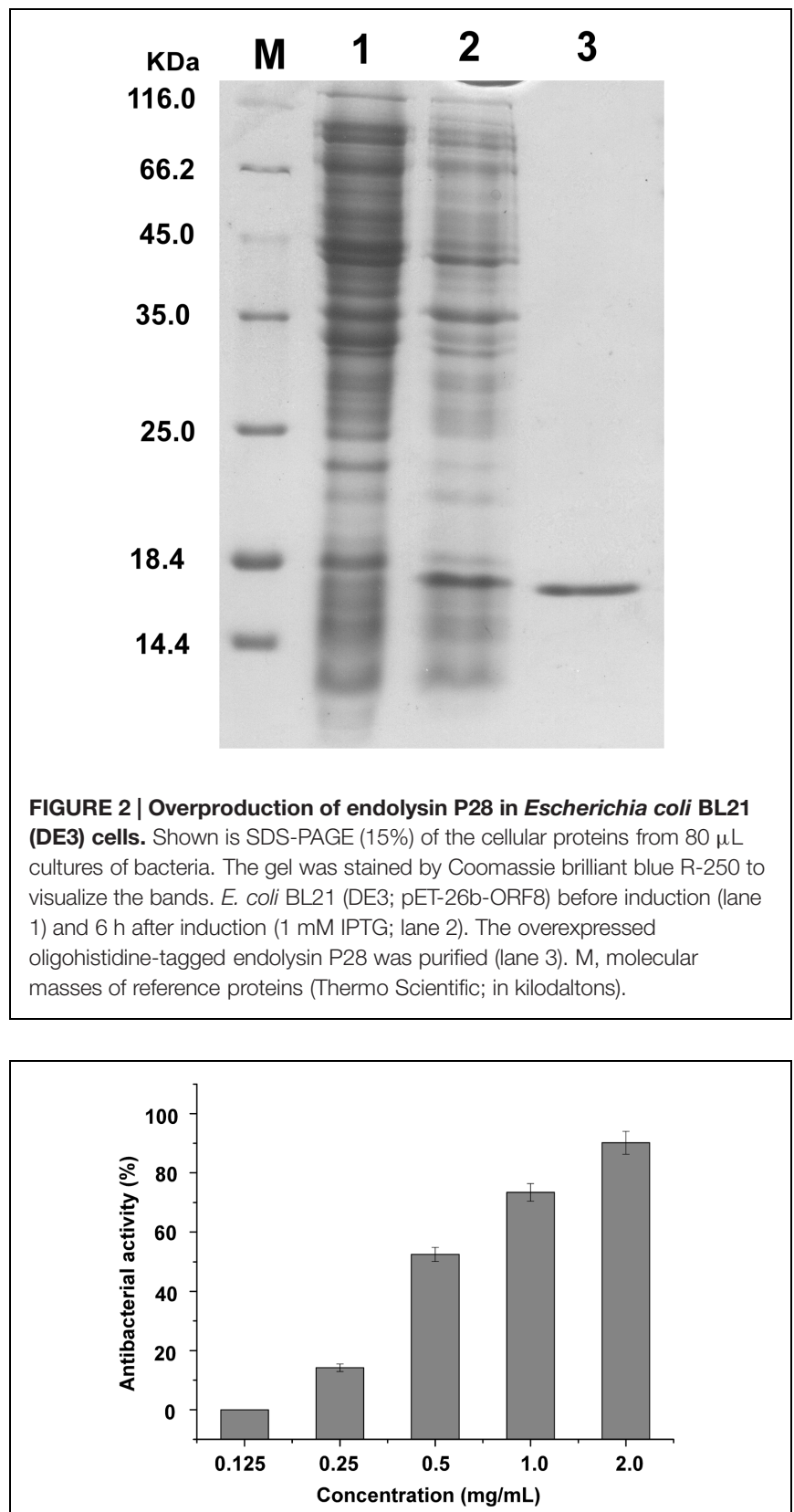

FIGURE 3 | Lytic activity of different concentration endolysin P28 against Stenotrophomonas maltophilia P28. One hundred microliter purified endolysin P28 was mixed with $300 \mu \mathrm{L}$ cell suspension $\left(\mathrm{OD}_{600}\right.$ $0.5 \pm 0.05)$. The concentration of the purified endolysin was changed while the reaction volumes of purified endolysin $(100 \mu \mathrm{L})$ and cell suspension $\left(300 \mu \mathrm{L}\right.$ ) remained unchanged. After incubation for $1 \mathrm{~h}$ at $30^{\circ} \mathrm{C}$, the CFUs of the mixture was determined and the antibacterial activity was calculated as described in the section "Materials and Methods". The data were statistically analyzed by using the Origin8.1 program. All experiments were repeated at least three times. Mean values $( \pm S D)$ are shown.

2013). Apparently endolysin P28 showed a broader antibacterial spectrum than maltocin P28 (Table 1). Endolysin P28 was able to lyse all of the tested Gram-positive bacteria and exhibited high lytic activity against three Gram-negative bacteria, Klebsiella
A

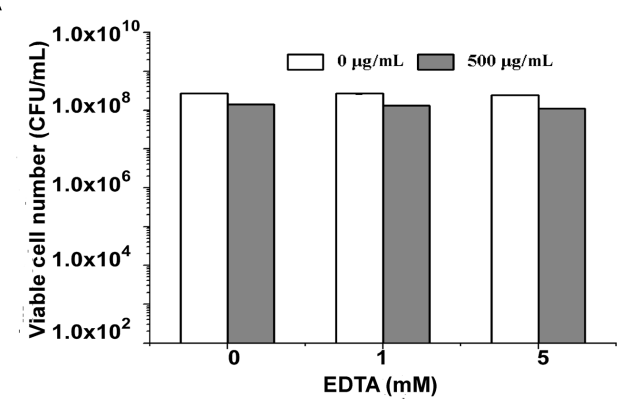

B



FIGURE 4 | Lytic activity of endolysin P28 over a range of

ethylenediaminetetraacetic acid (EDTA). The viable cell numbers (CFUs) of S. maltophilia P28 (A) and P. aeruginosa ATCC 15692 (B) after the addition of $500 \mu \mathrm{g}$ endolysin P28 were examined. The cells were treated with different concentrations of EDTA $(0,1,5 \mathrm{mM})$ for 30 min before the endolysin P28 was added. After incubation for $1 \mathrm{~h}$ at $30^{\circ} \mathrm{C}$, the CFUs of the mixture was determined and the antibacterial activity was calculated as described in the section "Materials and Methods". Error bars are the means \pm standard deviation of three independent assays.

pneumoniae ssp. pneumoniae, Shigella flexneri, Xanthomonas citri ssp. malvacearum (Figure 6). However, no activity was detected against $P$. fluorescens and Salmonella typhimurium.

\section{DISCUSSION}

The last decade has witnessed an increasing emergence of drug-resistant pathogens. Thus it is important to develop new alternatives to antibiotics. Phage endolysins have been reported to have good potential as a therapeutic agent for bacterial infections (Schmelcher et al., 2012). When added externally, they can cause a hole in the cell wall of the target bacterium through peptidoglycan digestion exerting a lethal effect (Fischetti, 2010). In general, exogenous endolysin is highly active against many Gram-positive species but ineffective against Gramnegative bacteria. It is probably due to the outer membrane existing in Gram-negative bacteria, which is impermeable to macromolecules and makes a physical barrier for endolysin to access the peptidoglycan layer (During et al., 1999; Fischetti, 2010).

Most endolysins from Gram-negative bacteriophage reported have only a catalytic domain. Some of them have a modular 
A

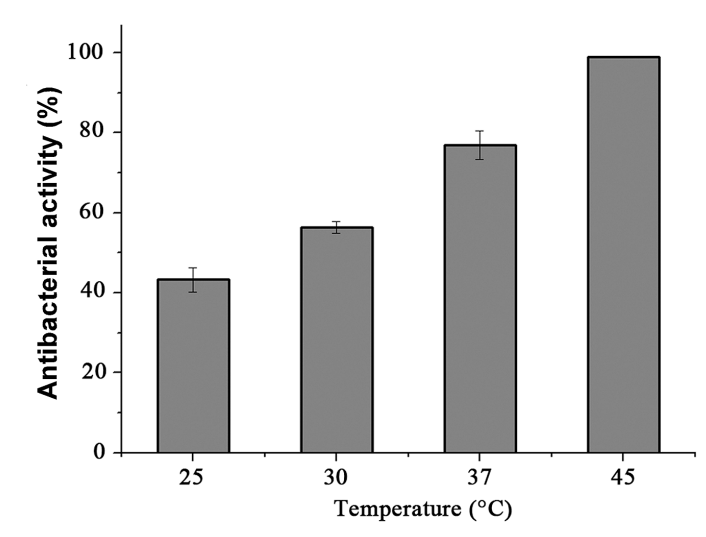

C

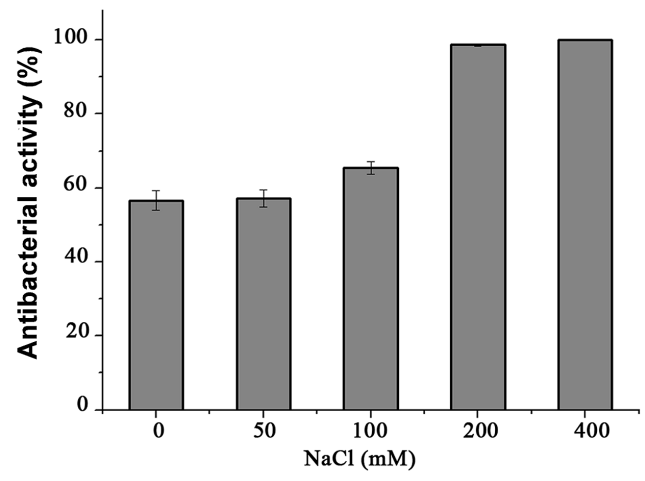

B

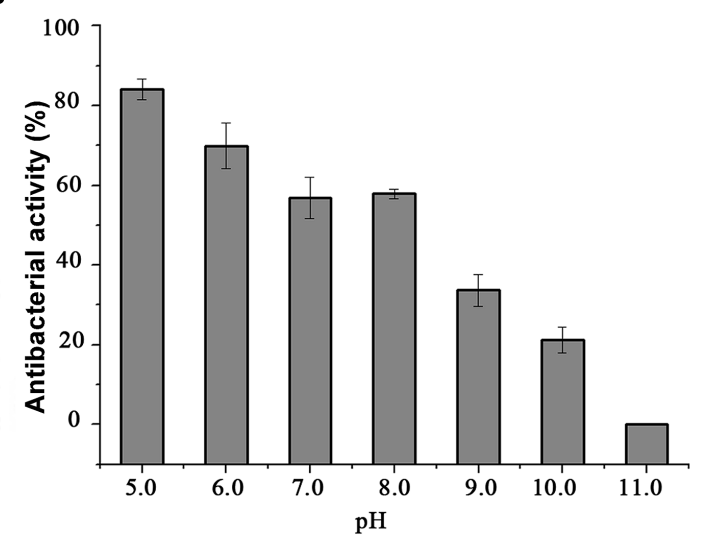

D

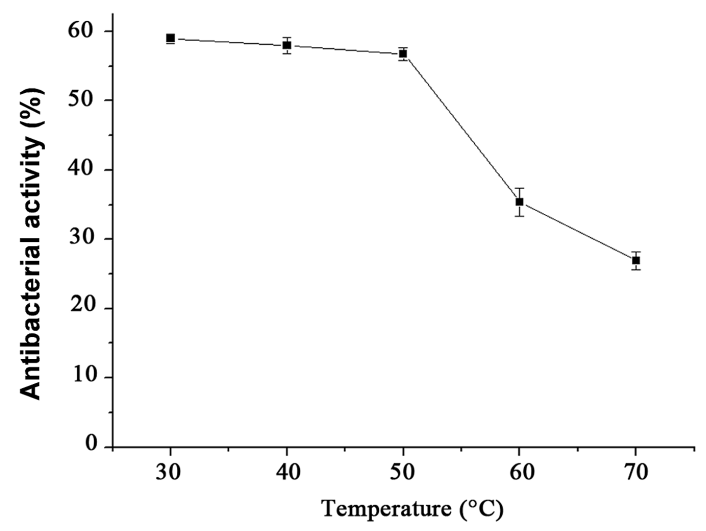

FIGURE 5 | Conditions for the enzymatic activity of the endolysin P28. The antimicrobial activity was performed at different temperatures for $1 \mathrm{~h}$ in $20 \mathrm{mM}$ Tris- $\mathrm{HCl}$ buffer, $\mathrm{pH} 7.0$ (A), and in buffers with different $\mathrm{pH}$ values for $1 \mathrm{~h}$ at $30^{\circ} \mathrm{C}$ (B). The influence of saline concentration on the lytic activity of endolysin was tested with different $\mathrm{NaCl}$ concentration to cell suspension for $1 \mathrm{~h}$ in $20 \mathrm{mM}$ Tris- $\mathrm{HCl}$ buffer, $\mathrm{pH} 7.0$ at $30^{\circ} \mathrm{C}$ (C). Thermostability of endolysin P28 was conducted by incubating endolysin P28 in different temperatures for $30 \mathrm{~min}$, and then the residual activity was calculated as described in the CFU reduction assay (D). Error bars are the means \pm standard deviation of three independent assays.

structure composed of a C-terminal catalytic domain and N-terminal cell wall binding domain (Briers et al., 2007; Fokine et al., 2008; Fischetti, 2010; Callewaert et al., 2011; Walmagh et al., 2013). Sequence analysis of endolysin P28 found no N-terminal cell wall binding domain or specific catalytic domain, rather it contained an N-terminal hydrophobic region (Figure 1B), which formed a putative helix domain. Some endolysins from phages of Gram-negative bacteria can destroy bacterial cells by means of a mechanism completely independent of their enzymatic activity (During et al., 1999; Orito et al., 2004). In these cases, it was found that helix-forming amphipathic peptides containing basic amino acid residues seem to interact with negatively charged membrane elements, such as lipopolysaccharide in Gram-negative bacteria (During et al., 1999; Lim et al., 2014). Therefore, we proposed that the N-terminal hydrophobic region of endolysin P28 should have the same function. Endolysin P28 showed a hydrolysis activity against peptidoglycan of E. coli and Bacillus subtilis through the turbidity reduction assay (data not shown). In addition to the four consensus motifs between endolysin P28 and lambda gpR, the catalytic residue Glu19 in lambda gpR playing an crucial role in the interaction of the enzyme with the GlcNAc of the peptidoglycan backbone is conserved in endolysin P28 (Glu25). So, further studies regarding the functions of N-terminal helix domain and Glu25 of endolysin P28 should be performed in the future.

Endolysin P28 had a good thermal stability, and showed a broad lytic spectrum against 14 out of 16 tested bacteria including medically important genera Aeromonas, Bacillus, Escherichia, Klebsiella, Listeria, Pseudomonas, Proteus, Salmonella, Shigella, Staphylococcus, and Xanthomonas. Since all the Gram-negative strains tested in this study are Gammaproteobacteria, further investigation into the effect of endolysin P28 on other bacterial species outside the two clusters of Gram-positive bacteria and Gammaproteobacteria is being carried out. Endolysin P28 could not lyse S. typhimurium and P. fluorescens. Gramnegative pathogens were protected by the presence of an outer membrane, preventing the entry of endolysins into the cell and reach the peptidoglycan (Nikaido, 2003). EDTA is a well-known used outer membrane permeabilizer that acts as a chelator by removing stabilizing cations from the outer 


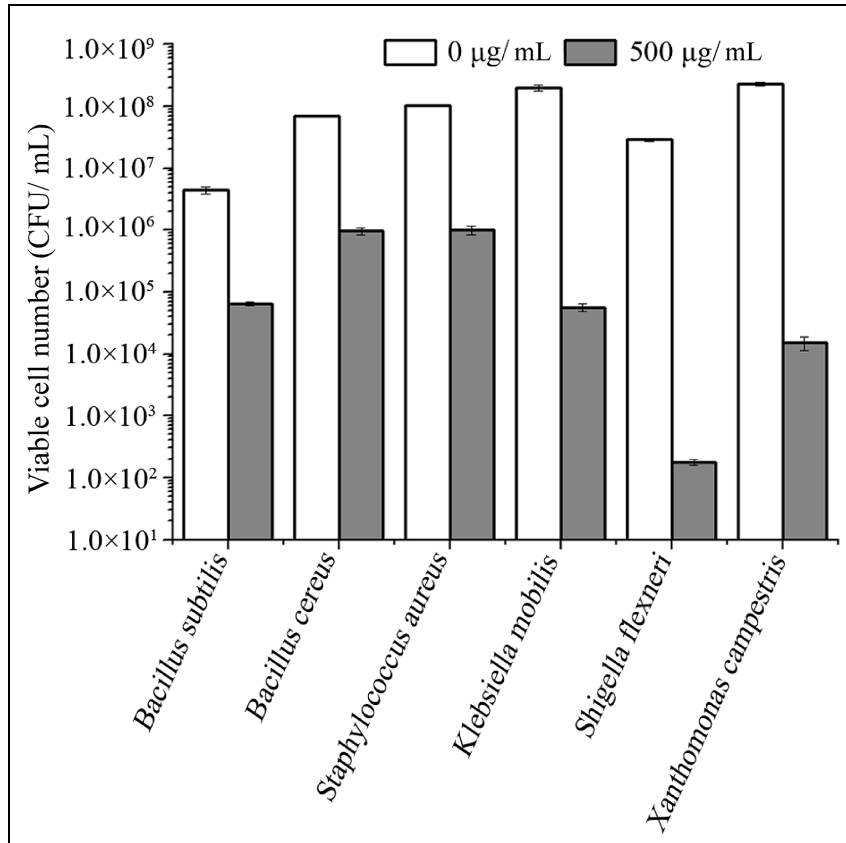

FIGURE 6 | Lytic activity of endolysin P28 against various Gram-positive and Gram-negative strains. Various exponentially growing bacteria were washed twice and resuspended in $20 \mathrm{mM}$ Tris- $\mathrm{HCl}$ buffer (pH 7.0). Three hundred microliter bacterial suspension $\left(\mathrm{OD}_{600} 0.5 \pm 0.05\right)$ was mixed with $100 \mu \mathrm{L}$ purified endolysin P28. After incubation for $1 \mathrm{~h}$ at $30^{\circ} \mathrm{C}$, the CFUs of the mixture was determined and the antibacterial activity was calculated as described in the section "Materials and Methods". Mean values $( \pm S D)$ are shown

membrane (Oliveira et al., 2014). In this study, we also found that EDTA could enhance the activity of endolysin P28 to $P$. aeruginosa. However, the tested strains were not treated by any outer membrane permeabilizer agent when the spectrum of

\section{REFERENCES}

Blackburn, N. T., and Clarke, A. J. (2001). Identification of four families of peptidoglycan lytic transglycosylases. J. Mol. Evol. 52, 78-84. doi: 10.1007/s002390010136

Bragg, R., van der Westhuizen, W., Lee, J. Y., Coetsee, E., and Boucher, C. (2014). Bacteriophages as potential treatment option for antibiotic resistant bacteria. Adv. Exp. Med. Biol. 807, 97-110. doi: 10.1007/978-81-322-1777-0_7

Briers, Y., Volckaert, G., Cornelissen, A., Lagaert, S., Michiels, C. W., Hertveldt, K., et al. (2007). Muralytic activity and modular structure of the endolysins of Pseudomonas aeruginosa bacteriophages phiKZ and EL. Mol. Microbiol. 65, 1334-1344. doi: 10.1111/j.1365-2958.2007.05870.x

Briers, Y., Walmagh, M., and Lavigne, R. (2011). Use of bacteriophage endolysin EL188 and outer membrane permeabilizers against Pseudomonas aeruginosa. J. Appl. Microbiol. 110, 778-785. doi: 10.1111/j.1365-2672.2010.04931.x

Brooke, J. S. (2012). Stenotrophomonas maltophilia: an emerging global opportunistic pathogen. Clin. Microbiol. Rev. 25, 2-41. doi: 10.1128/CMR.00019-11

Callewaert, L., Walmagh, M., Michiels, C. W., and Lavigne, R. (2011). Food applications of bacterial cell wall hydrolases. Curr. Opin. Biotechnol. 22, 164171. doi: 10.1016/j.copbio.2010.10.012

Coffey, B., Mills, S., Coffey, A., McAuliffe, O., and Ross, R. P. (2010). Phage and their lysins as biocontrol agents for food safety applications. Annu. endolysin P28 was detected. Thus, the reason for endolysin P28 ineffective against some strains may be the endolysin P28 could not pass through outer member and reach their peptidoglycans. Several Salmonella phage endolysins, such as Lys68, SPN1S, and SPN9CC, have been characterized (Lim et al., 2012, 2014; Oliveira et al., 2014). They have a wide spectrum of antibacterial activity against Gram-negative bacteria but no effect on the Gram-positive bacteria tested. More strains should be detected to ascertain how the antibacterial spectrum of endolysin is associated with the bacterial characteristics.

As S. maltophilia P28 is EDTA resistant, we have no wonder that EDTA had no effect on the sensitivity of $S$. maltophilia P28 to endolysin P28. However, it is important to note that endolysin P28 has antibacterial activity against other Gramnegative bacteria without EDTA treatment. To our knowledge, few endolysins and engineered phage lytic enzymes have been reported to have this property (Lai et al., 2011; Lukacik et al., 2012, 2013; Schmelcher et al., 2012). The antibacterial rate of endolysin P28 was more than 99\% against six tested strains, which were three Gram-positive and three Gram-negative strains. The viable cell numbers of three Gram-positive strains were reduced about 2 logs, while the viable cell numbers of three Gram-negative strains were reduced more than 3 logs, especially the viable cell number of $S$. flexneri was reduced more than 5 logs (Figure 6). These results suggested that endolysin P28 is a potential therapeutic agent against both Gram-positive and Gram-negative pathogenic strains.

\section{ACKNOWLEDGMENT}

This work was supported by grants from the Natural Science Foundation of Hubei Province, China (No. 2014CFB699) and National Infrastructure of Natural Resources for Science and Technology Program of China (No. NIMR-2014-8).

Rev. Food Sci. Technol. 1, 449-468. doi: 10.1146/annurev.food.102308.1 24046

During, K., Porsch, P., Mahn, A., Brinkmann, O., and Gieffers, W. (1999). The non-enzymatic microbicidal activity of lysozymes. FEBS Lett. 449, 93-100. doi: 10.1016/S0014-5793(99)00405-6

Falagas, M. E., Kastoris, A. C., Vouloumanou, E. K., and Dimopoulos, G. (2009). Community-acquired Stenotrophomonas maltophilia infections: a systematic review. Eur. J. Clin. Microbiol. Infect. Dis. 28, 719-730. doi: 10.1007/s10096009-0709-5

Farris, M. H., and Steinberg, A. D. (2014). Mitrecin A, an endolysin-like bacteriolytic enzyme from a newly isolated soil streptomycete. Lett. Appl. Microbiol. 58, 493-502. doi: 10.1111/lam.12220

Fischetti, V. A. (2008). Bacteriophage lysins as effective antibacterials. Curr. Opin. Microbiol. 11, 393-400. doi: 10.1016/j.mib.2008.09.012

Fischetti, V. A. (2010). Bacteriophage endolysins: a novel anti-infective to control Gram-positive pathogens. Int. J. Med. Microbiol. 300, 357-362. doi: 10.1016/j.ijmm.2010.04.002

Fokine, A., Miroshnikov, K. A., Shneider, M. M., Mesyanzhinov, V. V., and Rossmann, M. G. (2008). Structure of the bacteriophage phi KZ lytic transglycosylase gp144. J. Biol. Chem. 283, 7242-7250. doi: 10.1074/jbc.M709398200

Gilmer, D. B., Schmitz, J. E., Euler, C. W., and Fischetti, V. A. (2013). Novel bacteriophage lysin with broad lytic activity protects against mixed 
infection by Streptococcus pyogenes and methicillin-resistant Staphylococcus aureus. Antimicrob. Agents Chemother. 57, 2743-2750. doi: 10.1128/AAC.02 526-12

Grandgirard, D., Loeffler, J. M., Fischetti, V. A., and Leib, S. L. (2008). Phage lytic enzyme Cpl-1 for antibacterial therapy in experimental pneumococcal meningitis. J. Infect. Dis. 197, 1519-1522. doi: 10.1086/587942

Guzoglu, N., Demirkol, F. N., and Aliefendioglu, D. (2015). Haemorrhagic pneumonia caused by Stenotrophomonas maltophilia in two newborns. J. Infect. Dev. Ctries. 18, 533-535. doi: 10.3855/jidc.5463

Hotta, G., Matsumura, Y., Kato, K., Nakano, S., Yunoki, T., Yamamoto, M., et al. (2014). Risk factors and outcomes of Stenotrophomonas maltophilia bacteraemia: a comparison with bacteraemia caused by Pseudomonas aeruginosa and Acinetobacter species. PLoS ONE 9:e112208. doi: 10.1371/journal.pone.0112208

Jespers, L., Sonveaux, E., and Fastrez, J. (1992). Is the bacteriophage lambda lysozyme an evolutionary link or a hybrid between the $\mathrm{C}$ and $\mathrm{V}$-type lysozymes? Homology analysis and detection of the catalytic amino acid residues. J. Mol. Biol. 228, 529-538. doi: 10.1016/0022-2836(92)90840-G

Lai, M. J., Lin, N. T., Hu, A. R., Soo, P. C., Chen, L. K., Chen, L. H., et al. (2011). Antibacterial activity of Acinetobacter baumannii phage Phi AB2 endolysin (LysAB2) against both Gram-positive and Gram-negative bacteria. Appl. Microbiol. Biotechnol. 90, 529-539. doi: 10.1007/s00253-011-3 104-y

Lim, J. A., Shin, H., Heu, S., and Ryu, S. (2014). Exogenous lytic activity of SPN9CC endolysin against gram-negative bacteria. J. Microbiol. Biotechnol. 24, 803-811.

Lim, J. A., Shin, H., Kang, D. H., and Ryu, S. (2012). Characterization of endolysin from a Salmonella Typhimurium-infecting bacteriophage SPN1S. Res. Microbiol. 163, 233-241. doi: 10.1016/j.resmic.2012.01.002

Liu, J., Chen, P., Zheng, C., and Huang, Y. P. (2013). Characterization of maltocin P28, a novel phage tail-like bacteriocin from Stenotrophomonas maltophilia. Appl. Environ. Microbiol. 79, 5593-5600. doi: 10.1128/AEM.01648-13

Loessner, M. J. (2005). Bacteriophage endolysins-current state of research and applications. Curr. Opin. Microbiol. 8, 480-487. doi: 10.1016/j.mib.2005.0 6.002

Looney, W. J., Narita, M., and Muhlemann, K. (2009). Stenotrophomonas maltophilia: an emerging opportunist human pathogen. Lancet Infect. Dis. 9, 312-323. doi: 10.1016/S1473-3099(09)70083-0

Lukacik, P., Barnard, T. J., Hinnebusch, B. J., and Buchanan, S. K. (2013). Specific targeting and killing of Gram-negative pathogens with an engineered phage lytic enzyme. Virulence 4, 90-91. doi: 10.4161/viru.22683

Lukacik, P., Barnard, T. J., Keller, P. W., Chaturvedi, K. S., Seddiki, N., Fairman, J., et al. (2012). Structural engineering of a phage lysin that targets Gram-negative pathogens. Proc. Natl. Acad. Sci. U.S.A. 109, 9857-9862. doi: 10.1073/pnas.1203472109

Nikaido, H. (2003). Molecular basis of bacterial outer membrane permeability revisited. Microbiol. Mol. Biol. Rev. 67, 593-656. doi: 10.1128/MMBR.67.4.593656.2003

Oey, M., Lohse, M., Scharff, L. B., Kreikemeyer, B., and Bock, R. (2009). Plastid production of protein antibiotics against pneumonia via a new strategy for highlevel expression of antimicrobial proteins. Proc. Natl. Acad. Sci. U.S.A. 106, 6579-6584. doi: 10.1073/pnas.0813146106
Oliveira, H., Thiagarajan, V., Walmagh, M., Sillankorva, S., Lavigne, R., Neves-Petersen, M. T., et al. (2014). A thermostable Salmonella phage endolysin, Lys68, with broad bactericidal properties against GramNegative pathogens in presence of weak acids. PLOS ONE 9:e108376. doi: 10.1371/journal.pone.0108376

Orito, Y., Morita, M., Hori, K., Unno, H., and Tanji, Y. (2004). Bacillus amyloliquefaciens phage endolysin can enhance permeability of Pseudomonas aeruginosa outer membrane and induce cell lysis. Appl. Microbiol. Biot. 65, 105-109. doi: 10.1007/s00253-003-1522-1

Rodriguez, L., Martinez, B., Zhou, Y., Rodriguez, A., Donovan, D. M., and Garcia, P. (2011). Lytic activity of the virion-associated peptidoglycan hydrolase HydH5 of Staphylococcus aureus bacteriophage vB_SauS-phiIPLA88. BMC Microbiol. 11:138. doi: 10.1186/1471-2180-11-138

Sambrook, J. (1989). Molecular Cloning: A Laboratory Manual [M], 3rd Edn. New York, NY: Cold Spring Harbor Laboratory.

Sánchez, M. B. (2015). Antibiotic resistance in the opportunistic pathogen Stenotrophomonas maltophilia. Front. Microbiol. 6:658. doi: 10.3389/fmicb.2015.00658

Schmelcher, M., Donovan, D. M., and Loessner, M. J. (2012). Bacteriophage endolysins as novel antimicrobials. Future Microbiol. 7, 1147-1171. doi: 10.2217/fmb.12.97

Schmitz, J. E., Schuch, R., and Fischetti, V. A. (2010). Identifying active phage lysins through functional viral metagenomics. Appl. Environ. Microbiol. 76, 7181-7187. doi: 10.1128/AEM.00732-10

Sood, S., Vaid, V. K., and Bhartiya, H. (2013). Meningitis due to Stenotrophomonas maltophilia after a Neurosurgical Procedure. J. Clin. Diagn. Res. 7, 1696-1697. doi: 10.7860/JCDR/2013/5614.3248

Tan, C. K., Liaw, S. J., Yu, C. J., Teng, L. J., and Hsueh, P. R. (2008). Extensively drug-resistant Stenotrophomonas maltophilia in a tertiary care hospital in Taiwan: microbiologic characteristics, clinical features, and outcomes. Diagn. Microbiol. Infect. Dis. 60, 205-210. doi: 10.1016/j.diagmicrobio.2007.09.007

Trignano, E., Manz, M. J., Fallico, N., Maffei, M., Marongiu, F., Campus, G. V., et al. (2014). First report of digital skin ulcer with Stenotrophomonas maltophilia infection in an immunocompetent patient. In Vivo 28, 259-261.

Walmagh, M., Boczkowska, B., Grymonprez, B., Briers, Y., Drulis-Kawa, Z., and Lavigne, R. (2013). Characterization of five novel endolysins from Gramnegative infecting bacteriophages. J. Microbiol. Biotechnol. 97, 4369-4375. doi: 10.1007/s00253-012-4294-7

Yang, H., Yu, J., and Wei, H. (2014). Engineered bacteriophage lysins as novel anti-infectives. Front. Microbiol. 5:542. doi: 10.3389/fmicb.2014.00542

Conflict of Interest Statement: The authors declare that the research was conducted in the absence of any commercial or financial relationships that could be construed as a potential conflict of interest.

Copyright (c) 2015 Dong, Zhu, Chen, Ye and Huang. This is an open-access article distributed under the terms of the Creative Commons Attribution License (CC BY). The use, distribution or reproduction in other forums is permitted, provided the original author(s) or licensor are credited and that the original publication in this journal is cited, in accordance with accepted academic practice. No use, distribution or reproduction is permitted which does not comply with these terms. 